\title{
A hypothesis on the biological origins and social evolution of music and dance
}

\author{
Tianyan Wang ${ }^{1,2,3 *}$ \\ School of Life Science, Tsinghua University, Beijing, China \\ ${ }^{2}$ Ocean Science and Technology Division, Graduate School at Shenzhen, Tsinghua University, Shenzhen, China \\ ${ }^{3}$ Gene and Cell Engineering Laboratory, Shenzhen Institutes of Advanced Technology, Chinese Academy of Sciences, Shenzhen, China
}

\section{Edited by:}

Josef P. Rauschecker, Georgetown University School of Medicine, USA

\section{Reviewed by:}

Mireille Besson, Centre National de la Recherche Scientifique, Institut de Neurosciences Cognitives de la

Meditarranée, France

Elvira Brattico, University of

Helsinki, Finland

\section{*Correspondence:}

Tianyan Wang, Ocean Science and Technology Division, Graduate School at Shenzhen, Tsinghua University, Room 304, Building L, Tsinghua Campus, University Town of Shenzhen, Shenzhen 518055, China

e-mail: tianyanwang@hotmail.com
The origins of music and musical emotions is still an enigma, here I propose a comprehensive hypothesis on the origins and evolution of music, dance, and speech from a biological and sociological perspective. I suggest that every pitch interval between neighboring notes in music represents corresponding movement pattern through interpreting the Doppler effect of sound, which not only provides a possible explanation for the transposition invariance of music, but also integrates music and dance into a common form-rhythmic movements. Accordingly, investigating the origins of music poses the question: why do humans appreciate rhythmic movements? I suggest that human appreciation of rhythmic movements and rhythmic events developed from the natural selection of organisms adapting to the internal and external rhythmic environments. The perception and production of, as well as synchronization with external and internal rhythms are so vital for an organism's survival and reproduction, that animals have a rhythm-related reward and emotion (RRRE) system. The RRRE system enables the appreciation of rhythmic movements and events, and is integral to the origination of music, dance and speech. The first type of rewards and emotions (rhythm-related rewards and emotions, RRREs) are evoked by music and dance, and have biological and social functions, which in turn, promote the evolution of music, dance and speech. These functions also evoke a second type of rewards and emotions, which I name society-related rewards and emotions (SRREs). The neural circuits of RRREs and SRREs develop in species formation and personal growth, with congenital and acquired characteristics, respectively, namely music is the combination of nature and culture. This hypothesis provides probable selection pressures and outlines the evolution of music, dance, and speech. The links between the Doppler effect and the RRREs and SRREs can be empirically tested, making the current hypothesis scientifically concrete.

Keywords: music, dance, speech, emotion, origin, evolution, entrainment, Doppler effect

\section{INTRODUCTION}

Music exists ubiquitously across human history and human culture (D'errico et al., 2003; Conard et al., 2009), and has the ability to evoke rewards, and other positive and negative emotions (Blood et al., 1999; Blood and Zatorre, 2001; Menon and Levitin, 2005; Koelsch et al., 2006; Wieczorkowska et al., 2006; Koelsch, 2014). However, the origins of music and musical emotions is still largely an enigma (Brown et al., 2000; Schyff, 2014).

Since Darwin (1871), more and more scientists believe that human music must be a biological adaptation (Wallin et al., 2001; Mithen, 2009). Studies on twins (Drayna, 2001) and congenital amusia (Peretz et al., 2007; Tan et al., 2014) indicated that pitch recognition provides a hereditary basis for musical ability. However, the critical question we need to answer is what selection pressures are responsible for the origins of music? Charles Darwin proposed that, like bird song and dance, human music and dance were promoted by sexual selection (Darwin,
1871). Sexual selection, considered as a selection pressure, has been acknowledged and developed by other scientists (Miller, 2000). Our life begins with a lullaby, matures with a wedding march and ends in funeral music. The social functions of music are so important, that many scientists argue that music originated and developed from social activities: strengthening the mother-baby connection (Dissanayake, 2000; Trehub, 2003) and social cohesion (Brown, 2000a; Freeman, 2000; Mithen, 2007). And there are also many hypotheses on the origins of musical emotions (Wallin et al., 2001; Brattico et al., 2009; Perlovsky, 2010; Altenmüller et al., 2013; Juslin, 2013; Patel and Iversen, 2014). All of these theories and hypotheses are reasonable to explain some aspects of music and musical emotions and will be significant in guiding future research, however, there are also more or less deficits (Hagen and Bryant, 2003). What's still under debate is which selection pressures are responsible for the origins and evolution of music and musical emotions. 
Music is never alone, it is often accompanied by dance and other synchronized movements not only in humans (Repp, 2005), but also in other animals (Patel et al., 2009; Schachner et al., 2009; Cook et al., 2013). Music perception is also closely related to movement (Phillips-Silver and Trainor, 2005; Zatorre et al., 2007; Trainor et al., 2009; Maes et al., 2014). Besides dance and movement, music shares some common characteristics and neural circuits with speech (Falk, 2000; Marler, 2000; Zatorre et al., 2002; Patel, 2003; Koelsch et al., 2005; Masataka, 2009). And there is debate on the evolutionary relationship between music and speech (Bickerton, 2000; Molino, 2000). There are four main possibilities: music and speech evolved independently, both of them evolved from a common ancestor, music evolved from speech or speech evolved from music (Molino, 2000; Mithen, 2005; Besson et al., 2011).

If music appreciation is an evolutionary adaptation, is there any significant selection pressure for music and musical emotions? Is there any profound relation among music, dance and speech in the process of species evolution? Here I propose a hypothesis on the origins and evolution of music, dance, and speech from an biological and sociological perspective. Firstly, I integrate music and dance into a common form-rhythmic movements-through the Doppler effect of sound. Secondly, I suggest that the adaptation of organisms to external and internal rhythms is what has driven the formation of rhythm-related reward and emotion (RRRE) system, which enables animals to appreciate, search for and produce rhythmic movements and events. In part three and four, I elaborate on the origins and evolution of music, dance, and speech in animal and human society. In the last part, I use this hypothesis to reasonably explain results from previous studies, and give some directions on interesting avenues for future research.

\section{RHYTHMIC MOVEMENTS ARE THE BASIC ELEMENTS OF MUSIC AND DANCE}

Cookery and romance have no direct connection with human evolution. However, their basic elements, food and sex are essential for survival and reproduction, respectively, which are integral to evolution. Similarly, if there is a significant biological basis for music and dance, the first question we need to answer is: what are the basic elements of music and dance? Although there are several elements such as, rhythm, melody, pitch, harmony, timbre, and dynamics in a solo (Jones et al., 2010), only pitch and rhythm are the basic ones (Platel et al., 1997; Krumhansl, 2000; Trainor and Unrau, 2012), which could alter emotional, behavioral, and physiological states in human beings (Schellenberg et al., 2000) and some kinds of animals (Snowdon and Teie, 2013). It seems that melody (the combination of rhythm and pitch) could be defined as the prototypical music, which has the ability to evoke rewards and emotions.

Melody is a series of rhythmic pitches in a time line (Cariani and Micheyl, 2012). In classical physics, the Doppler effect of sound indicates that the relative velocity between a sound source and the observer would influence the observed frequency $f$ compare to the emitted frequency $f_{0}$ in a stationary medium (Rosen and Gothard, 2009). The relationships between $f$ and $f_{0}$ are given by the formulas in Table 1. These formulas also indicated that a certain ratio of frequency $\left(f / f_{0}\right)$ denotes a certain relationship between $v_{s}$ (the velocity of the source relative to the medium) and $v_{r}$ (the velocity of the receiver relative to the medium). I suggest that animals detect and calculate the source's movement pattern through their own movement pattern and the frequency ratio of sound. This ability may be valuable for the survival and reproduction, for example, some bats, whales and dolphins exploit the Doppler effect in echolocation for navigating and hunting (Nelson and Maciver, 2006; Au and Simmons, 2007; Ulanovsky and Moss, 2008; Parker et al., 2013; Corcoran and Conner, 2014). I suggest the human brain processes pitch intervals in music into movements by the interpreting of Doppler effect of sound, namely interpreting every pitch interval into a corresponding velocity of an abstract sounding event.

The frequency ratio of every pitch interval in music is determined by equal temperament, which was first presented in high precision by the Chinese prince Zhu Zaiyu (Chinese: 朱載䏴) in 1584 (Kuttner, 1975). Therefore, rhythmic pitch intervals (the temporal sequence of frequency ratio between neighboring notes) in a melody represent rhythmic movements (Table 2). The rhythmic moving subject here is neither the instrument, nor the performer, but an abstract sounding event in our unconscious mind.

This hypothesis could explain an unsolved problem in music perception, transposition invariance-with the correct pitch intervals between the notes, people could recognize a familiar tune irrespective of the absolute pitch of the beginning note (McDermott and Oxenham, 2008; Cariani and Micheyl, 2012; Trainor and Unrau, 2012). The reason may be that the invariant pitch intervals are representative of an invariant movement pattern.

Melody and dance are temporal sequences of pitches and movements, respectively. As such, melody and dance can be integrated into a common form-rhythmic movements (Figure 1),

Table 1 | The relationships between observed frequency $\boldsymbol{f}$ and emitted frequency $f_{0}$ in the Doppler effect (Rosen and Gothard, 2009).

\begin{tabular}{llll}
\hline & Observed frequency & Receiver & Source \\
\hline Situation A & $f=f_{0} c /\left(c+v_{s}\right)$ & stationary & $v_{s}=c\left(f_{0}-f\right) / f$ \\
Situation B & $f=f_{0}\left(c+v_{r}\right) / c$ & $v_{r}=c\left(f-f_{0}\right) / f_{0}$ & stationary \\
Situation C & $f=f_{0}\left(c+v_{r}\right) /\left(c+v_{s}\right)$ & moving $\left(v_{r}\right)$ & moving $\left(v_{s}\right)$ \\
\hline
\end{tabular}

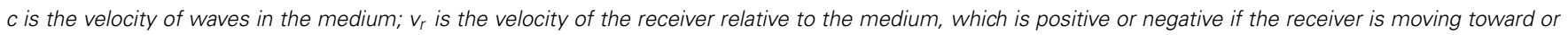

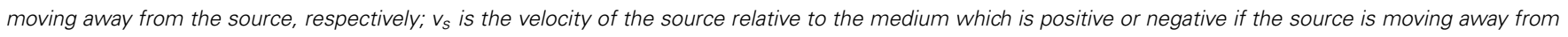
or moving toward the receiver, respectively. 


\begin{tabular}{|c|c|c|c|}
\hline Pitch interval & Ratio of frequency & $\begin{array}{l}\text { Velocity of } \\
\text { ASE }\end{array}$ & $\begin{array}{c}\text { Velocity of ASE } \\
\text { in } \operatorname{air}(\mathbf{m} / \mathbf{s})\end{array}$ \\
\hline & $f / f_{0}$ & $c\left(f_{0} / f-1\right)$ & $340\left(f_{0} / f-1\right)$ \\
\hline-12 & 0.50000000 & $1.000 \mathrm{c}$ & 340.00 \\
\hline-11 & 0.52973155 & $0.888 c$ & 301.83 \\
\hline-10 & 0.56123102 & $0.782 c$ & 265.81 \\
\hline-9 & 0.59460356 & $0.682 c$ & 231.81 \\
\hline-8 & 0.62996052 & $0.587 c$ & 199.72 \\
\hline-7 & 0.66741993 & $0.498 c$ & 169.42 \\
\hline-6 & 0.70710678 & $0.414 c$ & 140.83 \\
\hline-5 & 0.74915354 & $0.335 c$ & 113.85 \\
\hline-4 & 0.79370053 & $0.260 c$ & 88.37 \\
\hline-3 & 0.84089642 & $0.189 c$ & 64.33 \\
\hline-2 & 0.89089872 & $0.122 c$ & 41.64 \\
\hline-1 & 0.94387431 & $0.059 c$ & 20.22 \\
\hline 0 & 1.00000000 & 0 & 0.00 \\
\hline 1 & 1.05946309 & $-0.056 c$ & -19.08 \\
\hline 2 & 1.12246205 & $-0.109 c$ & -37.09 \\
\hline 3 & 1.18920712 & $-0.159 c$ & -54.10 \\
\hline 4 & 1.25992105 & $-0.206 c$ & -70.14 \\
\hline 5 & 1.33483985 & $-0.251 c$ & -85.29 \\
\hline 6 & 1.41421356 & $-0.293 c$ & -99.58 \\
\hline 7 & 1.49830708 & $-0.333 c$ & -113.08 \\
\hline 8 & 1.58740105 & $-0.370 c$ & -125.81 \\
\hline 9 & 1.68179283 & $-0.405 c$ & -137.83 \\
\hline 10 & 1.78179744 & $-0.439 c$ & -149.18 \\
\hline 11 & 1.88774863 & $-0.470 c$ & -159.89 \\
\hline 12 & 2.00000000 & $-0.500 c$ & -170.00 \\
\hline
\end{tabular}

ASE, the abstract sounding events in our unconscious mind.

with the perceiving, producing and synchronizing with these rhythmic movements inducing reward feelings, and other positive and negative emotions. The next question is: why and how rhythmic movements induce this emotional arousal?

\section{THE GENERATION OF RHYTHM-RELATED REWARD AND EMOTION (RRRE) SYSTEM}

There are both external and internal rhythmic events that are relevant to an organism (Vitaterna et al., 2001; Rutter et al., 2002). The coordination of internal rhythm to an external rhythm is called entrainment (Merker et al., 2009; McAuley, 2010; PhillipsSilver et al., 2010) or sensorimotor synchronization (SMS) especially when the internal rhythm is movement (Repp and Su, 2013). Phillips-Silver et al. (2010) suggested there are various entrainments that build upon pre-existing adaptations which enable organisms to perceive, produce and synchronize with rhythmic stimuli.

I suggest that living environments such as water, air and trees, are rich in rhythmic movements produced through natural forces (wind and tide, etc.) and biological forces (animal activities). Both arboreal and aquatic animals have adapted in order to thrive in the flexible supports in which they live (Thorpe et al., 2009; Shepard et al., 2013). For example, killer whales and their prey, sea lions, both have distinguished swimming skills to deal with the fluctuant ocean environment for successful predation and escape, respectively (Vila et al., 2008). Animal movements also influence and are influenced by the surrounding flexible supports, which add additional forces to the animal locomotor system (Thorpe et al., 2009). Animals have to perceive and predict external and internal movements to plan and produce the next movement (Figure 2). I suggest that both types of movements of animals and those of the flexible supports are rhythms rich that can fit and interact with each other, as well as a lock and key. I define this as the sensorimotor synchronization to rhythms of flexible supports (SMS-RFS, Figure 2). Since the minimum cost of transport $\left(\mathrm{COT}_{\min }\right)$ is critical for survival (Shepard et al., 2013), orangutans do use tree sway to reduce the energetic cost of gap crossing (Thorpe et al., 2007), and it is less costly for northern gannets to fly with the wind than against it (Amelineau et al., 2014). I propose the evolutionary values of SMS-RFS are energy-saving, time-saving and efficiency of locomotion, which are vital to fierce competition for survival and reproduction.

Since the SMS-RFS and the entrainments/SMS to other rhythms (E/S-OR) are critical for survival and reproduction of organisms, I propose that they drive the generation of a RRRE system (Figure 2). The reward evoked by rhythm is probably not secondary, but primary, as rewards evoked by food and sex (Sescousse et al., 2013). Rhythmic events in nature also connect with various phenomena and lead to corresponding results, contributing to the generation and activation of the RRRE system. These rhythmic events lead to both beneficial and harmful results, arousing corresponding positive and negative everyday emotions, respectively. Under natural selection, the connections between rhythmic events and emotions are inherently established. Some rhythmic events arouse positive emotions and encourage animals close to it; on the contrary, some arouse negative emotions and drive animals to keep away from it. The RRRE system enables animals to appreciate rhythmic events, to perceive, produce and synchronize with rhythmic events, as well as to adopt advantageous and avoid disadvantageous rhythmic events.

\section{THE BIOLOGICAL ORIGINS AND SOCIAL EVOLUTION OF PRO-MUSIC, PRO-DANCE, AND PRO-SPEECH IN NONHUMAN ANIMALS}

I suggest that the RRRE system (Figure 2) enables animals to enjoy, search and produce rhythmic events, and drives the generation of entertainment rhythmic movements (ERMs), which are characterized by rhythm, aesthetics and fluency, and likely involve the refinements of everyday movements. Most of the ERMs probably are the refinements of everyday movements that have evolutionary value, and some ERMs may be driven by the RRRE system independently and have no obvious evolutionary value originally. The ERMs of the body and limbs is pro-dance, such as the dance of bird of paradise and crane (Mandoki, 2014), and the non-vocal rhythmic sound generated in this process is pro-instrumental music (Figure 3), such as the sound made by palm cockatoo's drumming (Wood, 1984; Gray et al., 2001). The rhythmic vocal sound generated by the rhythmic movement of vocal cords, such as bird and whale songs (Payne, 2000; Gray et al., 2001), is both pro-vocal music and pro-speech. Pro-language 


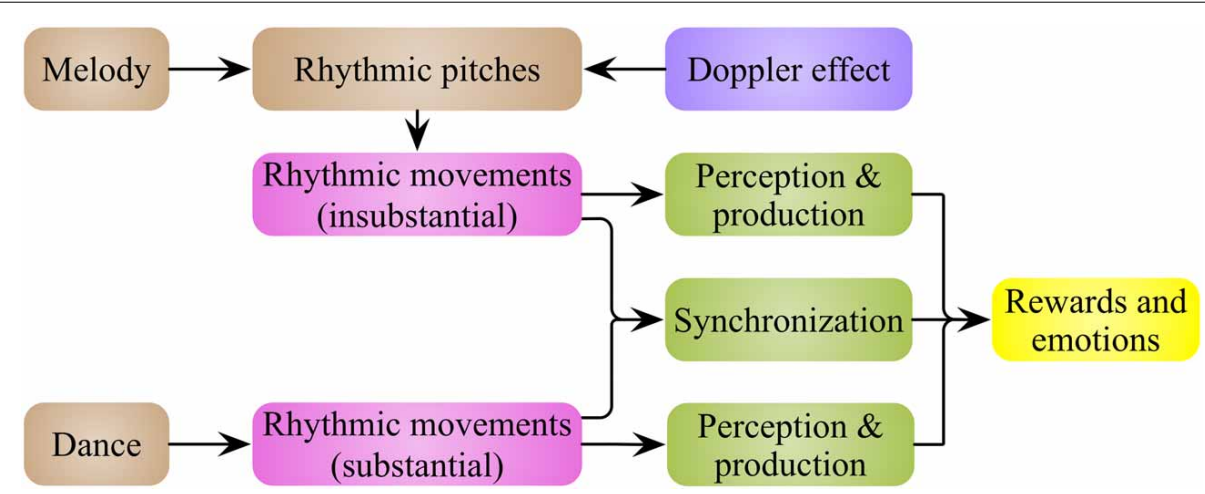

FIGURE 1 | Rhythmic movements are the basic elements of music and dance. Music and dance are a series of rhythmic pitches and movements in time line, respectively. Based on Doppler effect of sound, rhythmic pitch intervals in music represent the rhythmic movements of an abstract event. It means that music and dance could be integrated into a common form-rhythmic movements. Rewards and emotions are evoked by the production, perception and synchronization of the rhythmic movements.

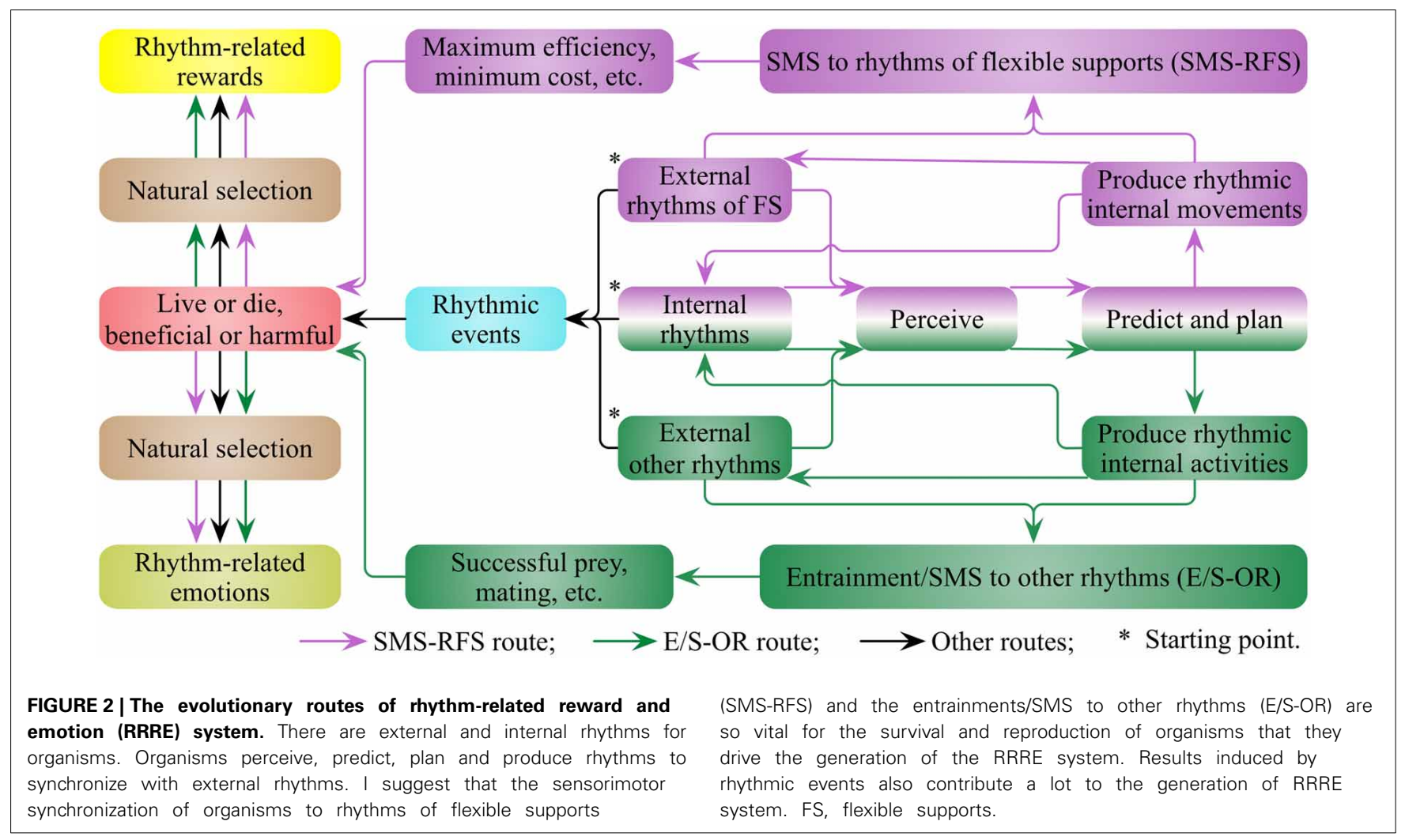

is the vocal sound that includes simple information. Therefore rhythmic vocal is often a combination of pro-vocal music, prospeech and pro-language for animals, and the boundary among them is obscure.

The first type of rewards and emotions (rhythm-related rewards and emotions, RRREs) evoked by pro-music, pro-dance, pro-speech, and pro-language have biological functions (e.g., sexual selection) and social functions (e.g., fostering the social bonding). These biological and social roles are largely defined by their biological origins, and provide a driving force for their continued biological and social evolution. These functions also enable the development of a second type of rewards and emotions, which I name society-related rewards and emotions (SRREs, Figure 3).

\section{THE BIOLOGICAL ORIGINS AND SOCIAL EVOLUTION OF MUSIC, DANCE, AND LANGUAGE IN HUMAN}

I propose that human beings inherit and develop the RRRE system from their aquatic and arboreal ancestors. On one hand, the coevolution of pro-vocal music, pro-speech, pro-language, and vocal cords leads to vocal music and language (Figure 4). Language is a vocal tool derived from pro-speech and evolved from pro-language for the purpose of complex information 


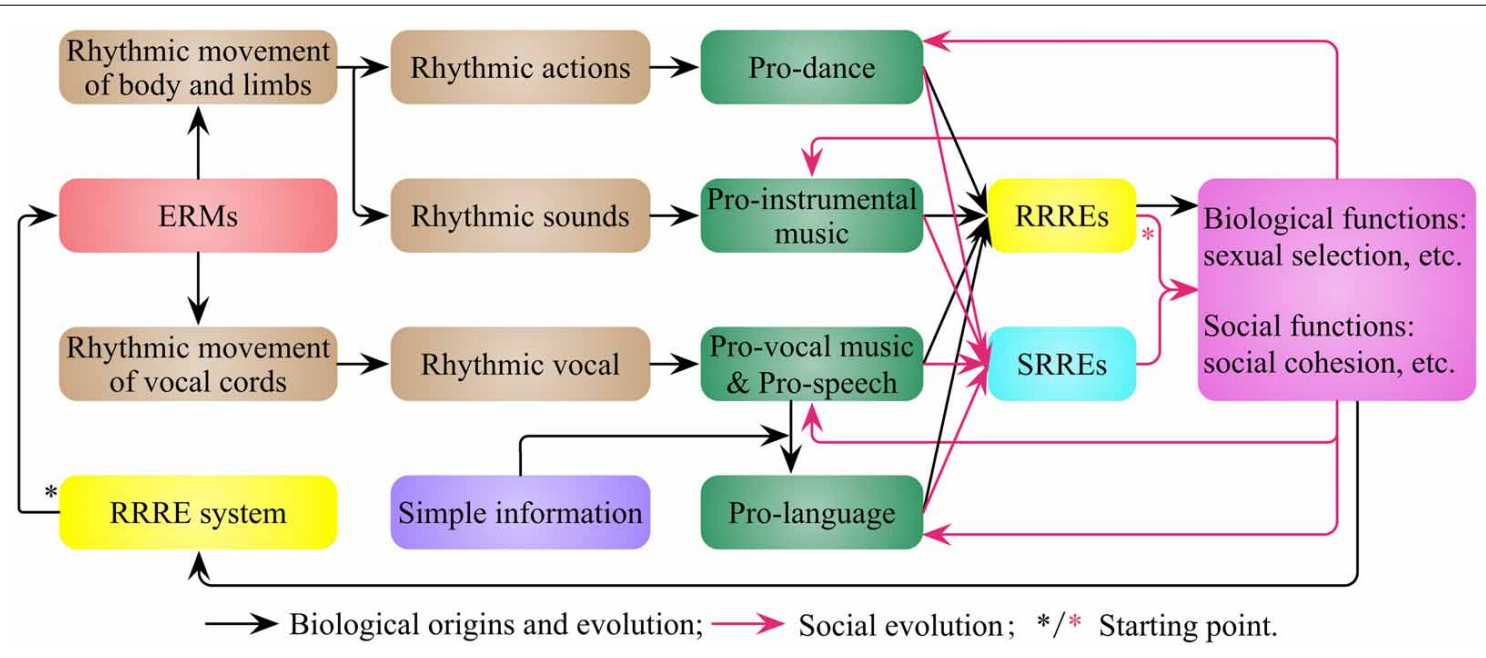

FIGURE 3 | The biological origins and social evolution of pro-music, pro-dance, and pro-speech in nonhuman animals. The rhythm-related reward and emotion (RRRE) system (Figure 2) makes animals produce entertainment rhythmic movements (ERMs) and leads to pro-music, pro-dance, pro-speech and pro-language. The first type of rewards and emotions (rhythm-related rewards and emotions, RRREs) evoked by them have biological and social functions. These functions are the results of their biological origins, as well as the driving force for their evolution. These functions also enable the development of a second type of rewards and emotions (society-related rewards and emotions, SRREs).

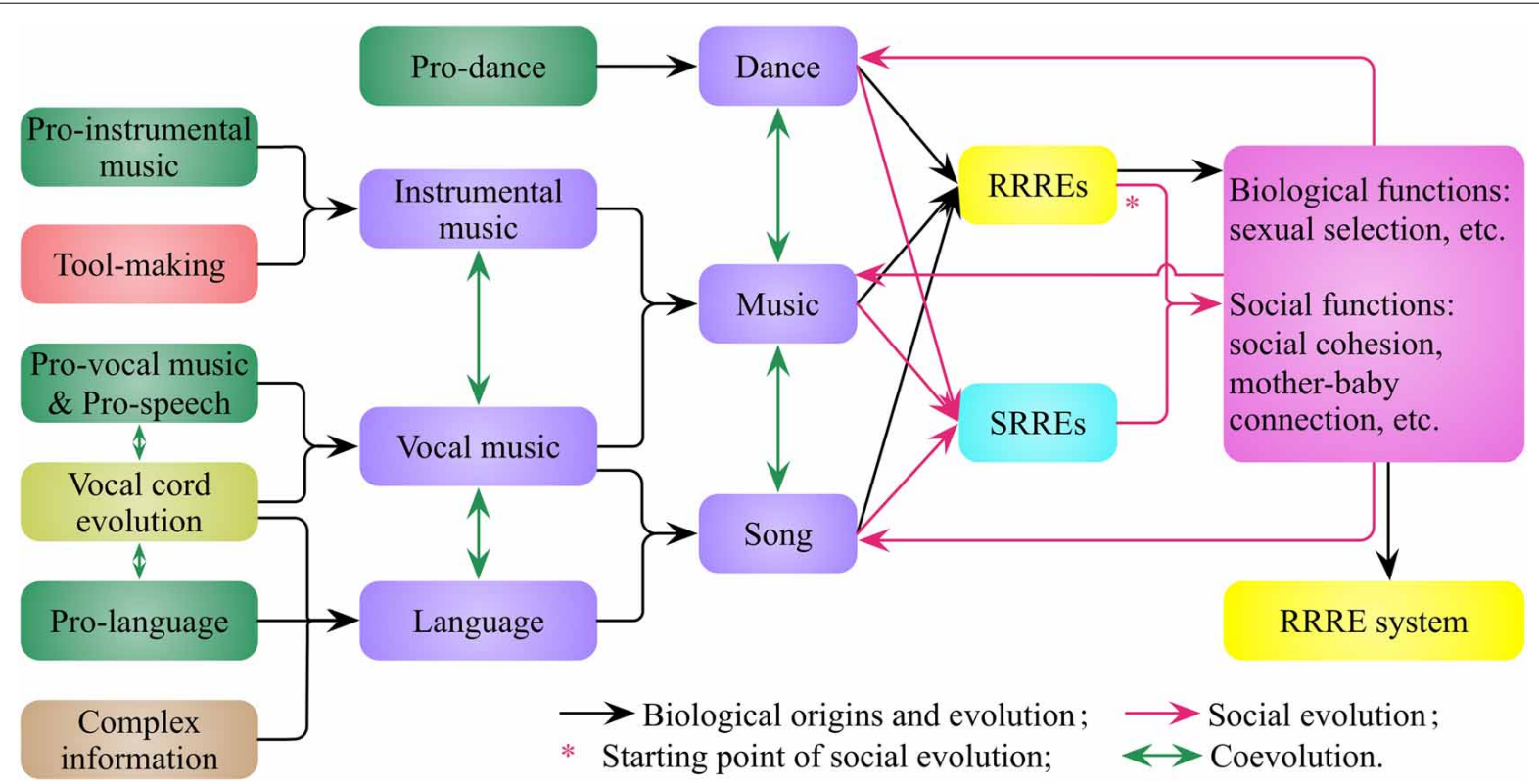

FIGURE 4 | The biological origins and social evolution of music, dance, and language in humans. Tool making promotes the origins of instrumental music, vocal cord evolution promotes the origins of vocal music and language, and there are coevolutions among music, dance, and language. The rhythm-related rewards and emotions (RRREs) evoked by music and dance give rise to their biological and social functions, which in turn promote the biological and social evolution of music and dance, and enable the development of society-related rewards and emotions (SRREs) of music and dance. The neural circuits of RRREs and SRREs develop in species formation and personal growth, with congenital and acquired characteristics, respectively. communication. On the other hand, tool making leads to instrumental music, such as the bone and ivory flutes from Hohle Fels and Vogelherd in Germany (Conard et al., 2009), and the bone flutes of Neanderthal (Gray et al., 2001). A melody represents two things, one is rhythmic audio event, the other is rhythmic movement interpreted by the Doppler effect (Figure 1), and both of them trigger the human RRRE system to evoke rewards and emotions.

The first type of rewards and emotions-RRREs—evoked by music and dance are beneficial for both individuals and populations. These rewards and emotions lead to biological functions, such as sexual selection (Miller, 2000), and social functions, such 
as fostering the mother-baby connection (Dissanayake, 2000; Trehub, 2003) and social cohesion (Brown, 2000a; Freeman, 2000; Mithen, 2007). These functions in turn promote the biological and social evolution of music and dance, also enable music and dance to evoke a second type of rewards and emotionsSRREs (Figure 4). I suggest that the neural circuits of RRREs and SRREs develop both congenital and acquired characteristics during species formation and personal growth, respectively. On one hand, from a biological perspective, the genetic basis of human musicality has undergone macroevolution and microevolution in the development of RRREs and SRREs, respectively. On the other hand, from a sociological perspective, the types and applications of music have undergone microevolution and macroevolution in the development of RRREs and SRREs, respectively. Therefore, music, dance, and speech are the combination of nature (biological origins) and culture (social evolution), and can induce both RRREs and SRREs.

I suggest that the biological origins and social evolution of music endow the rewards and emotions evoked by music with species-specific and individual-specific traits. I propose that different characteristics in melodies corresponding to rhythmic movements, represent corresponding rhythmic events, and induce corresponding emotions that can be applied in corresponding social activities (Figure 5). Generally, music with a high pitch, large pitch range and fast tempo could induce happiness, excitement or fear (Gabrielsson and Juslin, 2003; Hunter and Schellenberg, 2010; Juslin and Sloboda, 2011), maybe because those characteristics represent fast and powerful movements/events such as fight, flight, competition, or weather storms. On the contrast, music with a low pitch, narrow pitch range and slow rhythm could induce sadness or peace (Gabrielsson and Juslin, 2003; Hunter and Schellenberg, 2010; Juslin and Sloboda, 2011), perhaps because these characteristics represent slow and powerless movements/events such as weakness, wound, failure, or a gentle breeze. This means that some common music characteristics may induce corresponding emotions through the RRRE system across human culture, which is consistent with the fact that basic emotions (happiness, sadness, and fear) in Western music can be recognized by the native African population (Fritz et al., 2009). However, even the same music may induce individual specific emotions (Brattico and Jacobsen, 2009; Mas-Herrero et al., 2013), with the development of SRREs depending mainly on the cultural, as well as individual experiences.

\section{DISCUSSION}

Music exists ubiquitously across human history and human culture (D'errico et al., 2003; Conard et al., 2009). What's still under debate is which selection pressures are responsible for the origins and evolution of music and musical emotions. Many reasonable theories, such as sexual selection (Darwin, 1871; Miller, 2000), mother-baby connection (Dissanayake, 2000; Trehub, 2003) and social cohesion (Brown, 2000a; Freeman, 2000; Mithen, 2007) have been previously considered as the selection pressures for music evolution. However, I suggest the primary selection pressure for human musicality is identical with the selection pressure for the RRRE system-the adaptation of organisms to ubiquitously and variously internal and external rhythmic movements and events. Sexual selection and those social functions (e.g., mother-baby connection and social cohesion) are results of music's biological origins, as well as the driving force for the

\begin{tabular}{|c|c|c|c|c|c|}
\hline $\begin{array}{c}\text { Music } \\
\text { characteristics }\end{array}$ & Status of ASE & \multicolumn{2}{|c|}{$\begin{array}{l}\text { Movements / events } \\
\text { represented by the ASE }\end{array}$} & $\begin{array}{c}\text { Corresponding } \\
\text { emotions }\end{array}$ & Applications \\
\hline $\begin{array}{l}\text { High } \\
\text { pitches }\end{array}$ & $\begin{array}{l}\text { Moving } \\
\text { towards }\end{array}$ & \multirow{3}{*}{$\begin{array}{l}\text { Events are } \\
\text { powerful, } \\
\text { complicated, } \\
\text { fast and } \\
\text { moving } \\
\text { towards }\end{array}$} & \multirow{2}{*}{$\begin{array}{l}\text { Fight, flight } \\
\text { Victory, } \\
\text { competition }\end{array}$} & \multirow{2}{*}{$\begin{array}{l}\text { Agitated, } \\
\text { enthusiastic } \\
\text { Happy, } \\
\text { cheerful }\end{array}$} & Positive emotions \\
\hline Low pitches & $\begin{array}{l}\text { Moving } \\
\text { away }\end{array}$ & & & & \\
\hline $\begin{array}{l}\text { Large pitch } \\
\text { intervals }\end{array}$ & High speed & & $\begin{array}{l}\text { Mountain, } \\
\text { river, storm }\end{array}$ & $\begin{array}{l}\text { Exciting, } \\
\text { dramatic }\end{array}$ & $\begin{array}{l}\text { Festival, wedding, } \\
\text { celebration, etc. }\end{array}$ \\
\hline $\begin{array}{l}\text { Small pitch } \\
\text { intervals }\end{array}$ & Low speed & \multirow{3}{*}{$\begin{array}{l}\text { Events are } \\
\text { powerless, } \\
\text { simple, slow } \\
\text { and moving } \\
\text { away }\end{array}$} & Rest, peace & $\begin{array}{l}\text { Light, } \\
\text { comfortable }\end{array}$ & $\begin{array}{l}\text { Funeral, religion, } \\
\text { relaxation, etc. }\end{array}$ \\
\hline $\begin{array}{c}\text { Fast } \\
\text { rhythms }\end{array}$ & Fast change & & Failure, death & $\begin{array}{l}\text { Sad, } \\
\text { frustrated }\end{array}$ & $\Delta$ \\
\hline $\begin{array}{l}\text { Slow } \\
\text { rhythms }\end{array}$ & $\begin{array}{l}\text { Slow } \\
\text { change }\end{array}$ & & $\begin{array}{l}\text { Hill, creek, } \\
\text { breeze }\end{array}$ & $\begin{array}{l}\text { Dreamy, } \\
\text { leisurely }\end{array}$ & $\begin{array}{c}\text { Negative / neutral } \\
\text { emotions }\end{array}$ \\
\hline \multicolumn{6}{|c|}{$\begin{array}{ll}\text { FIGURE } 5 \text { | Different music characteristics represent different } & \text { fight, flight, competition or weather storms. In contrast, music with } \\
\text { rhythmic movements/events and induce corresponding emotions. } & \text { a low pitch, narrow pitch range and slow rhythm can induce } \\
\text { Generally, music with a high pitch, large pitch range and fast tempo } & \text { sadness or peace, perhaps due to these characteristics represent } \\
\text { induces happiness, excitement or fear, maybe because these } & \text { slow and powerless movements/events such as weakness, wound, } \\
\text { characteristics represent fast and powerful movements/events such as } & \text { failure or a gentle breeze. ASE, abstract sounding events. }\end{array}$} \\
\hline
\end{tabular}


evolution of music and the development of SRREs. That is to say, sexual selection and social cohesion are secondary selection pressures for the evolution of music.

Previous studies show that music can evoke rewards and emotions (Blood et al., 1999; Blood and Zatorre, 2001; Menon and Levitin, 2005; Koelsch et al., 2006; Koelsch, 2014). This hypothesis suggests the biological basis for music and dance is the RRRE system, whose selection pressure is the adaptation of organisms to ubiquitously external and internal rhythmic movements and events. As the synchronization of an organism to rhythmic events is even more pivotal to survival than food and sex to some extent, the reward evoked by rhythmic events is probably a primary reward, as with those evoked by food and sex (Sescousse et al., 2013). This may be the reason that music can trigger the mesolimbic reward system that is similarly triggered by food, sex and drugs (Blood and Zatorre, 2001; Zatorre and Salimpoor, 2013).

Previous studies indicate that body movement plays an important role in musical rhythm perception (Phillips-Silver and Trainor, 2005), also show music and movement shared a dynamic structure that supported universal expressions of emotion (Sievers et al., 2013). Here I propose certain pitch interval in music represents invariant movement pattern by the interpretation of Doppler effect. This hypothesis integrates music and dance in a common form-rhythmic movements. This may be able to explain the close relationships between music and movement. This hypothesis also provides a probable explanation for the transposition invariance of melodies in music perception, the reason may be that a series of invariant pitch intervals represent an invariant movement pattern.

Previous studies also indicate that music and speech may have evolved from a common ancestor (Brown, 2000b; Besson et al., 2011; Brandt et al., 2012). Here I suggest that speech and music are both derived from rhythmic vocalizations where the rhythmic vocal is often both pro-music and pro-speech, with the boundary between them obscure. Accordingly, I expect that more overlapping neural circuits for both music and speech should be existed in animals and children than human adults. Therefore, I suggest that vocal sounds used as signatures in some parrots (Berg et al., 2012), dolphins (King and Janik, 2013) and human tribe (Ammann et al., 2013) are both music and language to a degree.

I also suggest that SMS (one of the major characteristics of the RRRE system) is a necessary precondition for vocal mimicking. This view predicts that the ability to synchronize with an auditory rhythm likely exists in, but not confined to, vocal mimicking species. This is consistent with previous studies that SMS with music exists not only in multiple vocal mimicking species, such as humans (Repp, 2005) and parrots (Patel et al., 2009; Schachner et al., 2009), but also in non-vocal mimicking species, such as chimpanzees (Hattori et al., 2013) and sea lions (Cook et al., 2013).

This hypothesis suggests RRRE system shares both universal and species-specific characteristics. On one hand, the RRRE system is universal to both human and other animal species, especially those species living in flexible environments. That is consistent with the fact that almost all of the singing species such as canary, humpback whale, and white-handed gibbon are living in water, air or trees (Marler, 2000; Payne, 2000; Gray et al., 2001; Hauser and McDermott, 2003). It may be also the reason why whale song and bird song are similar in structure to human song and speech (Gray et al., 2001; Bolhuis et al., 2010). Furthermore, recent findings indicate that most songs of the hermit thrush make use of the same mathematical principles that underlie many human musical scales (Doolittle et al., 2014), and that chimpanzees prefer African and Indian music over silence (Mingle et al., 2014), both demonstrating common characteristics between humans and animals. Contrastingly, according to the proposed hypothesis, different species have differences between their RRRE systems, including differing sensorimotor organs. Even between chimpanzee and humans, there are differences in speech anatomy (Morley, 2003). It means that animals do not have to enjoy human music, but may enjoy it.

This hypothesis indicates that human musicality is not an all-or-none ability, but a comprehensive talent combining many sensorimotor abilities. More specifically, a sound musical talent in humans requires the entire RRRE system, as well as the sensorimotor systems for pitch, rhythm, and motion. Any deficit in these systems could lead to deficiency in a corresponding musical ability, but not musical abilities as a whole. For example, beat deaf amusia (Phillips-Silver et al., 2011; Palmer et al., 2014), pitch deaf amusia (Phillips-Silver et al., 2013), and specific musical anhedonia (Mas-Herrero et al., 2014) exhibit some normal musical perception capacities, despite having deficits in auditory beat perception, pitch cognition and musical pleasure extraction, respectively. In contrast, since music has close relations with the sensorimotor and emotional systems, if there is a deficit in those systems, music activity may play an alternative role to help recovery by facilitating the use and development of common neural circuits shared by music, movement, and emotion. This is consistent with previous studies in which music has the ability to cure patients who have movement or mental diseases (Altenmüller et al., 2009; Koelsch, 2014). For example, music can reduce pain and increase functional mobility in fibromyalgia (Garza-Villarreal et al., 2014).

Overall this hypothesis provides a probable selection pressure and outline for the evolution of music, dance and speech, and also reasonably explains most music phenomena investigated previously. I hope it shall enlighten future research on music, dance, and speech. Future experiments could allow for a clearer neurological definition of the RRRE system and SRRE circuits. The relationships between these two systems and the three phenomena in question (music, dance, and speech) should also be explored. Since optogenetics is a powerful technology that allows the fast and specific control of neural activities in brain of freely moving animals (Deisseroth, 2011), it has been applied in vocal learning research of songbirds successfully (Roberts et al., 2012; Roberts and Mooney, 2013). The optogenetics stimulation of rewarding regions efficiently guides the learning of sensory discrimination in mouse (Liu et al., 2014). Previous studies also indicate that music do effects physiology and psychology in mouse (Chikahisa et al., 2006; Angeluccia et al., 2007; Li et al., 2010; Uchiyama et al., 2012). Therefore I suggest that optogenetics can be used to establish animal models (mouse and/or bird) for music cognition on the behavioral, neural and genetic levels. 


\section{ACKNOWLEDGMENTS}

Thanks to Qian Zhang, Pan Ma, Shangjin Tan and Yi Hou, for assistance with the manuscript. Also thanks to Zhonghua Cai, Zhiying Chen and Chengyi He for their valuable suggestions. Further, I am particularly grateful to two anonymous reviewers for their valuable and detailed comments on earlier versions of this manuscript.

\section{REFERENCES}

Altenmüller, E., Kopiez, R., and Grewe, O. (2013). "Strong emotions in music: are they an evolutionary adaptation?," in Sound - Perception-Performance, Vol. 1 of Current Research in Systematic Musicology, ed R. Bader (Heidelberg: Springer), 131-156. doi: 10.1007/978-3-319-00107-4_5

Altenmüller, E., Marco-Pallares, J., Münte, T. F., and Schneider, S. (2009). Neural reorganization underlies improvement in stroke-induced motor dysfunction by music-supported therapy. Ann. N.Y. Acad. Sci. 1169, 395-405. doi: 10.1111/j.1749-6632.2009.04580.x

Amelineau, F., Peron, C., Lescroel, A., Authier, M., Provost, P., and Gremillet, D. (2014). Windscape and tortuosity shape the flight costs of northern gannets. J. Exp. Biol. 217, 876-885. doi: 10.1242/jeb.097915

Ammann, R., Keck, V., and Wassmann, J. (2013). The sound of a person: a musiccognitive study in the Finisterre Range in Papua New Guinea. Oceania 83, 63-87. doi: 10.1002/ocea.5012

Angeluccia, F., Riccib, E., Paduaa, L., Sabinob, A., and Tonali, P. A. (2007). Music exposure differentially alters the levels of brain-derived neurotrophic factor and nerve growth factor in the mouse hypothalamus. Neurosci. Lett. 429, 152-155. doi: 10.1016/j.neulet.2007.10.005

Au, W. W. L., and Simmons, J. A. (2007). Echolocation in dolphins and bats. Phys. Today 60, 40-45. doi: 10.1063/1.2784683

Berg, K. S., Delgado, S., Cortopassi, K. A., Beissinger, S. R., and Bradbury, J. W. (2012). Vertical transmission of learned signatures in a wild parrot. Proc. R. Soc. B Biol. Sci. 279, 585-591. doi: 10.1098/rspb.2011.0932

Besson, M., Chobert, J., and Marie, C. (2011). Transfer of training between music and speech: common processing, attention, and memory. Front. Psychol. 2:94. doi: 10.3389/fpsyg.2011.00094

Bickerton, D. (2000). "Can biomusicology learn from language evolution studies?," in The Origins of Music, eds N. L. Wallin, B. Merker, and S. Brown (Cambridge, MA: MIT Press), 153-163.

Blood, A. J., and Zatorre, R. J. (2001). Intensely pleasurable responses to music correlate with activity in brain regions implicated in reward and emotion. Proc. Natl. Acad. Sci. U.S.A. 98, 11818-11823. doi: 10.1073/pnas.191355898

Blood, A. J., Zatorre, R. J., Bermudez, P., and Evans, A. C. (1999). Emotional responses to pleasant and unpleasant music correlate with activity in paralimbic brain regions. Nat. Neurosci. 2, 382-387. doi: 10.1038/7299

Bolhuis, J. J., Okanoya, K., and Scharff, C. (2010). Twitter evolution: converging mechanisms in birdsong and human speech. Nat. Rev. Neurosci. 11, 747-759. doi: $10.1038 / \mathrm{nrn} 2931$

Brandt, A., Gebrian, M., and Slevc, L. R. (2012). Music and early language acquisition. Front. Psychol. 3:327. doi: 10.3389/fpsyg.2012.00327

Brattico, E., Brattico, P., and Jacobsen, T. (2009). The origins of the aesthetic enjoyment of music - A review of the literature. Music. Sci. 13, 15-39. doi: $10.1177 / 1029864909013002031$

Brattico, E., and Jacobsen, T. (2009). Subjective appraisal of music neuroimaging evidence. Ann. N.Y. Acad. Sci. 1169, 308-317. doi: 10.1111/j.17496632.2009.04843.x

Brown, S., Merker, B., and Wallin, N. L. (2000). "An introduction to evolutionary musicology," in The Origins of Music, eds N. L. Wallin, B. Merker, and S. Brown (Cambridge, MA: MIT Press), 3-24.

Brown, S. (2000a). "Evolutionary models of music: from sexual selection to group selection," in Perspectives in Ethology: Evolution, Culture, and Behavior, eds F. Tonneau and N. S. Thompson (New York, NY: Springer), 231-281.

Brown, S. (2000b). “The 'musilanguage' model of music evolution,” in The Origins of Music, eds N. L. Wallin, B. Merker, and S. Brown (Cambridge, MA: MIT Press), 271-300.

Cariani, P., and Micheyl, C. (2012). “Toward a theory of information processing in auditory cortex," in The Human Auditory Cortex, eds D. Poeppel, T. Overath, A. N. Popper. and R. R. Fay (New York, NY: Springer), 351-390.
Chikahisa, S., Sei, H., Morishima, M., Sano, A., Kitaoka, K., Nakaya, Y., et al. (2006). Exposure to music in the perinatal period enhances learning performance and alters BDNF/TrkB signaling in mice as adults. Behav. Brain Res. 169, 312-319. doi: 10.1016/j.bbr.2006.01.021

Conard, N. J., Malina, M., and Münzel, S. C. (2009). New flutes document the earliest musical tradition in southwestern Germany. Nature 460, 737-740. doi: 10.1038/nature08169

Cook, P., Rouse, A., Wilson, M., and Reichmuth, C. (2013). A California sea lion (Zalophus californianus) can keep the beat: motor entrainment to rhythmic auditory stimuli in a non vocal mimic. J. Comp. Psychol. 127, 412-427. doi: $10.1037 / \mathrm{a} 0032345$

Corcoran, A. J., and Conner, W. E. (2014). Bats jamming bats: food competition through sonar interference. Science 346, 745-747. doi: 10.1126/science. 1259512

Darwin, C. (1871). The Descent of Man and Selection in Relation to Sex. London: John Murray. doi: 10.1037/12293-000

Deisseroth, K. (2011). Optogenetics. Nat. Methods 8, 26-29. doi: 10.1038/nmeth.f.324

D'errico, F., Henshilwood, C., Lawson, G., Vanhaeren, M., Tillier, A. M., Soressi, M., et al. (2003). Archaeological evidence for the emergence of language, symbolism, and music - An alternative multidisciplinary perspective. J. World Prehistory 17, 1-70. doi: 10.1023/A:1023980201043

Dissanayake, E. (2000). "Antecedents of the temporal arts in early mother-infant interaction," in The Origins of Music, eds N. L. Wallin, B. Merker, and S. Brown (Cambridge, MA: MIT Press), 389-410.

Doolittle, E. L., Gingras, B., Endres, D. M., and Fitch, W. T. (2014). Overtone-based pitch selection in hermit thrush song: unexpected convergence with scale construction in human music. Proc. Natl. Acad. Sci. U.S.A. 111, 16616-16621. doi: 10.1073/pnas.1406023111

Drayna, D. (2001). Genetic correlates of musical pitch recognition in humans. Science 291, 1969-1972. doi: 10.1126/science.291.5510.1969

Falk, D. (2000). "Hominid brain evolution and the origins of music," in The Origins of Music, eds N. L. Wallin, B. Merker, and S. Brown (Cambridge, MA: MIT Press), 197-216.

Freeman, W. (2000). "A neurobiological role of music in social bonding," in The Origins of Music, eds N. L. Wallin, B. Merker, and S. Brown (Cambridge, MA: MIT Press), 411-424.

Fritz, T., Jentschke, S., Gosselin, N., Sammler, D., Peretz, I., Turner, R., et al. (2009). Universal recognition of three basic emotions in music. Curr. Biol. 19, 573-576. doi: 10.1016/j.cub.2009.02.058

Gabrielsson, A., and Juslin, P. N. (2003). "Emotional expression in music," in Handbook of Affective Sciences, eds R. J. Davidson, K. R. Scherer, and H. Goldsmith (Oxford: Oxford University Press), 503-534.

Garza-Villarreal, E. A., Wilson, A. D., Vase, L., Brattico, E., Barrios, F. A., Jensen, T. S., et al. (2014). Music reduces pain and increases functional mobility in fibromyalgia. Front. Psychol. 5:90. doi: 10.3389/fpsyg.2014.00090

Gray, P. M., Krause, B., Atema, J., Payne, R., Krumhansl, C., and Baptista, L. (2001). The music of nature and the nature of music. Science 291, 52-54. doi: 10.1126/science.10.1126/SCIENCE. 1056960

Hagen, E. H., and Bryant, G. A. (2003). Music and dance as a coalition signaling system. Hum. Nat. 14, 21-51. doi: 10.1007/s12110-003-1015-z

Hattori, Y., Tomonaga, M., and Matsuzawa, T. (2013). Spontaneous synchronized tapping to an auditory rhythm in a chimpanzee. Sci. Rep. 3:1566. doi: 10.1038/ srep01566

Hauser, M. D., and McDermott, J. (2003). The evolution of the music faculty: a comparative perspective. Nat. Neurosci. 6, 663-668. doi: 10.1038/nn1080

Hunter, P. G., and Schellenberg, E. G. (2010). "Music and emotion," in Music perception, eds M. R. Jones, R. R. Fay, and A. N. Popper (New York, NY: Springer), $129-164$.

Jones, M. R., Fay, R. R., and Popper, A. N. (2010). Music Perception. New York, NY: Springer. doi: 10.1007/978-1-4419-6114-3

Juslin, P. N., and Sloboda, J. (2011). Handbook of Music and Emotion: Theory, Research, Applications. New York, NY: Oxford University Press.

Juslin, P. N. (2013). From everyday emotions to aesthetic emotions: towards a unified theory of musical emotions. Phys. Life Rev. 10, 235-266. doi: 10.1016/j.plrev.2013.05.008

King, S. L., and Janik, V. M. (2013). Bottlenose dolphins can use learned vocal labels to address each other. Proc. Natl. Acad. Sci. U.S.A. 110, 13216-13221. doi: 10.1073/pnas. 1304459110 
Koelsch, S., Fritz, T., Von Cramon, D. Y., Müller, K., and Friederici, A. D. (2006). Investigating emotion with music: an fMRI study. Hum. Brain Mapp. 27, 239-250. doi: 10.1002/hbm.20180

Koelsch, S., Gunter, T. C., Wittfoth, M., and Sammler, D. (2005). Interaction between syntax processing in language and in music: an ERP study. J. Cogn. Neurosci. 17, 1565-1577. doi: 10.1162/089892905774 597290

Koelsch, S. (2014). Brain correlates of music-evoked emotions. Nat. Rev. Neurosci. 15, 170-180. doi: 10.1038/nrn3666

Krumhansl, C. L. (2000). Rhythm and pitch in music cognition. Psychol. Bull. 126, 159-179. doi: 10.1037/0033-2909.126.1.159

Kuttner, F. A. (1975). Prince Chu Tsai-Yü's life and work: a re-evaluation of his contribution to equal temperament theory. Ethnomusicology 19, 163-206. doi: $10.2307 / 850355$

Li, W. J., Yu, H., Yang, J. M., Gao, J., Jiang, H., Feng, M., et al. (2010). Anxiolytic effect of music exposure on BDNF(Met/Met) transgenic mice. Brain Res. 1347, 71-79. doi: 10.1016/j.brainres.2010.05.080

Liu, Z., Zhou, J., Li, Y., Hu, F., Lu, Y., Ma, M., et al. (2014). Dorsal raphe neurons signal reward through 5-HT and glutamate. Neuron 81, 1360-1374. doi: 10.1016/j.neuron.2014.02.010

Maes, P.-J., Leman, M., Palmer, C., and Wanderley, M. M. (2014). Action-based effects on music perception. Front. Psychol. 4:1008. doi: 10.3389/fpsyg.2013.01008

Mandoki, K. (2014). Zoo-aesthetics: a natural step after Darwin. Semiotica 198, 61-91. doi: 10.1515/sem-2013-0102

Marler, P. (2000). "Origins of music and speech: Insights from animals," in The Origins of Music, eds N. L. Wallin, B. Merker, and S. Brown (Cambridge, MA: MIT Press), 31-48.

Masataka, N. (2009). The origins of language and the evolution of music: a comparative perspective. Phys. Life Rev. 6, 11-22. doi: 10.1016/j.plrev.2008.08.003

Mas-Herrero, E., Marco-Pallares, J., Lorenzo-Seva, U., Zatorre, R. J., and Rodriguez-Fornells, A. (2013). Individual differences in music reward experiences. Music Percept. 31, 118-138. doi: 10.1525/mp.2013.31.2.118

Mas-Herrero, E., Zatorre, R. J., Rodriguez-Fornells, A., and Marco-Pallarés, J. (2014). Dissociation between musical and monetary reward responses in specific musical anhedonia. Curr. Biol. 24, 699-704. doi: 10.1016/j.cub.2014.01.068

McAuley, J. D. (2010). “Tempo and rhythm," in Music Perception, eds M. R. Jones, R. R. Fay, and A. N. Popper (New York, NY: Springer), 165-199.

McDermott, J. H., and Oxenham, A. J. (2008). Music perception, pitch, and the auditory system. Curr. Opin. Neurobiol. 18, 452-463. doi: 10.1016/j.conb.2008.09.005

Menon, V., and Levitin, D. J. (2005). The rewards of music listening: response and physiological connectivity of the mesolimbic system. Neuroimage 28, 175-184. doi: 10.1016/j.neuroimage.2005.05.053

Merker, B. H., Madison, G. S., and Eckerdal, P. (2009). On the role and origin of isochrony in human rhythmic entrainment. Cortex 45, 4-17. doi: 10.1016/j.cortex.2008.06.011

Miller, G. (2000). "Evolution of human music through sexual selection," in The Origins of Music, eds N. L. Wallin, B. Merker, and S. Brown (Cambridge, MA: MIT Press), 329-360.

Mingle, M. E., Eppley, T. M., Campbell, M. W., Hall, K., Horner, V., and De Waal, F. (2014). Chimpanzees prefer African and Indian music over silence. J. Exp. Psychol. Anim. Learn. Cogn. 40, 502-505. doi: 10.1037/xan0000032

Mithen, S. (2005). The Singing Neanderthals: The Origins of Music, Language, Mind and Body. London: Weidenfeld \& Nicholson.

Mithen, S. (2009). The music instinct: the evolutionary basis of musicality. Ann. N.Y. Acad. Sci. 1169, 3-12. doi: 10.1111/j.1749-6632.2009. 04590.x

Mithen, S. J. (2007). "Music and the origin of modern humans," in Rethinking the Human Revolution, eds P. Mellars, K. Boyle, O. Bar-Yosef, and C. Stringer (Cambridge, MA: McDonald Institute), 107-117.

Molino, J. (2000). "Toward an evolutionary theory of music and language," in The Origins of Music, eds N. L. Wallin, B. Merker, and S. Brown (Cambridge, MA: MIT Press), 165-176.

Morley, I. (2003). The Evolutionary Origins and Archaeology of Music. Cambridge: Darwin College, Cambridge University.

Nelson, M. E., and Maciver, M. A. (2006). Sensory acquisition in active sensing systems. J. Comp. Physiol. A Neuroethol. Sens. Neural Behav. Physiol. 192, 573-586. doi: 10.1007/s00359-006-0099-4
Palmer, C., Lidji, P., and Peretz, I. (2014). Losing the beat: deficits in temporal coordination. Philos. Trans. R. Soc. Lond. B Biol. Sci. 369, 30405-30405. doi: 10.1098/rstb.2013.0405

Parker, J., Tsagkogeorga, G., Cotton, J. A., Liu, Y., Provero, P., Stupka, E., et al. (2013). Genome-wide signatures of convergent evolution in echolocating mammals. Nature 502, 228-231. doi: 10.1038/nature12511

Patel, A. D., and Iversen, J. R. (2014). The evolutionary neuroscience of musical beat perception: the Action Simulation for Auditory Prediction (ASAP) hypothesis. Front. Syst. Neurosci. 8:57. doi: 10.3389/fnsys.2014.00057

Patel, A. D., Iversen, J. R., Bregman, M. R., and Schulz, I. (2009). Experimental evidence for synchronization to a musical beat in a nonhuman animal. Curr. Biol. 19, 827-830. doi: 10.1016/j.cub.2009.03.038

Patel, A. D. (2003). Language, music, syntax and the brain. Nat. Neurosci. 6, 674-681. doi: 10.1038/nn1082

Payne, K. (2000). "The progressively changing songs of humpback whales: a window on the creative process in a wild animal," in The Origins of Music, eds N. L. Wallin, B. Merker, and S. Brown (Cambridge, MA: MIT Press), 135-150.

Peretz, I., Cummings, S., and Dubé, M.-P. (2007). The genetics of congenital amusia (tone deafness): a family-aggregation study. Am. J. Hum. Genet. 81, 582-588. doi: $10.1086 / 521337$

Perlovsky, L. (2010). Musical emotions: functions, origins, evolution. Phys. Life Rev. 7, 2-27. doi: 10.1016/j.plrev.2009.11.001

Phillips-Silver, J., Aktipis, C. A., and Bryant, G. A. (2010). The ecology of entrainment: foundations of coordinated rhythmic movement. Music Percept. 28, 3-14. doi: $10.1525 / \mathrm{mp} .2010 .28 .1 .3$

Phillips-Silver, J., Toiviainen, P., Gosselin, N., and Peretz, I. (2013). Amusic does not mean unmusical: beat perception and synchronization ability despite pitch deafness. Cogn. Neuropsychol. 30, 311-331. doi: 10.1080/02643294.2013. 863183

Phillips-Silver, J., Toiviainen, P., Gosselin, N., Piché, O., Nozaradan, S., Palmer, C., et al. (2011). Born to dance but beat deaf: a new form of congenital amusia. Neuropsychologia 49, 961-969. doi: 10.1016/j.neuropsychologia.2011.02.002

Phillips-Silver, J., and Trainor, L. J. (2005). Feeling the beat: movement influences infant rhythm perception. Science 308, 1430. doi: 10.1126/science.1110922

Platel, H., Price, C., Baron, J. C., Wise, R., Lambert, J., Frackowiak, R. S. J., et al. (1997). The structural components of music perception - A functional anatomical study. Brain 120, 229-243. doi: 10.1093/brain/120.2.229

Repp, B. H., and Su, Y.-H. (2013). Sensorimotor synchronization: a review of recent research (2006-2012). Psychon. Bull. Rev. 20, 403-452. doi: 10.3758/s13423-0120371-2

Repp, B. H. (2005). Sensorimotor synchronization: a review of the tapping literature. Psychon. Bull. Rev. 12, 969-992. doi: 10.3758/BF03206433

Roberts, T. F., Gobes, S. M. H., Murugan, M., Ölveczky, B. P., and Mooney, R. (2012). Motor circuits are required to encode a sensory model for imitative learning. Nat. Neurosci. 15, 1454-1459. doi: 10.1038/nn.3206

Roberts, T. F., and Mooney, R. (2013). Motor circuits help encode auditory memories of vocal models used to guide vocal learning. Hear. Res. 303, 48-57. doi: 10.1016/j.heares.2013.01.009

Rosen, J. G., and Gothard, L. Q. (2009). Encyclopedia of Physical Science. New York, NY: Facts on File.

Rutter, J., Reick, M., and McKnight, S. L. (2002). Metabolism and the control of circadian rhythms. Annu. Rev. Biochem. 71, 307-331. doi: 10.1146/annurev.biochem.71.090501.142857

Schachner, A., Brady, T. F., Pepperberg, I. M., and Hauser, M. D. (2009). Spontaneous motor entrainment to music in multiple vocal mimicking species. Curr. Biol. 19, 831-836. doi: 10.1016/j.cub.2009.03.061

Schellenberg, E. G., Krysciak, A. M., and Campbell, R. J. (2000). Perceiving emotion in melody: interactive effects of pitch and rhythm. Music Percept. 18, 155-171. doi: $10.2307 / 40285907$

Schyff, D. V. D. (2014). Music, culture and the evolution of the human mind: looking beyond dichotomies. Hell. J. Music Educ. Cult. 4. Available online at: http:// hejmec.eu/journal/index.php/HeJMEC/article/view/40

Sescousse, G., Caldu, X., Segura, B., and Dreher, J. C. (2013). Processing of primary and secondary rewards: a quantitative meta-analysis and review of human functional neuroimaging studies. Neurosci. Biobehav. Rev. 37, 681-696. doi: 10.1016/j.neubiorev.2013.02.002

Shepard, E. L. C., Wilson, R. P., Rees, W. G., Grundy, E., Lambertucci, S. A., and Vosper, S. B. (2013). Energy landscapes shape animal movement ecology. Am. Nat. 182, 298-312. doi: 10.1086/671257 
Sievers, B., Polansky, L., Casey, M., and Wheatley, T. (2013). Music and movement share a dynamic structure that supports universal expressions of emotion. Proc. Natl. Acad. Sci. U.S.A. 110, 70-75. doi: 10.1073/pnas.12090 23110

Snowdon, C. T., and Teie, D. (2013). "Emotional communication in monkeys: music to their ears?," in The Evolution of Emotional Communication: From Sounds in Nonhuman Mammals to Speech and Music in Man, eds E. Altenmüller, S. Schmidt, and E. Zimmermann (Oxford: Oxford Scholarship Online), 133-151.

Tan, Y. T., McPherson, G. E., Peretz, I., Berkovic, S. F., and Wilson, S. J. (2014). The genetic basis of music ability. Front. Psychol. 5:658. doi: 10.3389/fpsyg.2014.00658

Thorpe, S. K. S., Crompton, R. H., and Alexander, R. M. (2007). Orangutans use compliant branches to lower the energetic cost of locomotion. Biol. Lett. 3, 253-256. doi: 10.1098/rsbl.2007.0049

Thorpe, S. K. S., Holder, R., and Crompton, R. H. (2009). Orangutans employ unique strategies to control branch flexibility. Proc. Natl. Acad. Sci. U.S.A. 106, 12646-12651. doi: 10.1073/pnas.0811537106

Trainor, L. J., Gao, X., Lei, J.-J., Lehtovaara, K., and Harris, L. R. (2009). The primal role of the vestibular system in determining musical rhythm. Cortex 45, 35-43. doi: 10.1016/j.cortex.2007.10.014

Trainor, L. J., and Unrau, A. (2012). "Development of pitch and music perception," in Human Auditory Development, eds L. Werner, R. R. Fay, and A. N. Popper (New York, NY: Springer), 223-254.

Trehub, S. E. (2003). The developmental origins of musicality. Nat. Neurosci. 6, 669-673. doi: 10.1038/nn1084

Uchiyama, M., Jin, X., Zhang, Q., Amano, A., Watanabe, T., and Niimi, M. (2012). Music exposure induced prolongation of cardiac allograft survival and generated regulatory CD4(+) cells in mice. Transplant. Proc. 44, 1076-1079. doi: 10.1016/j.transproceed.2012.02.008

Ulanovsky, N., and Moss, C. F. (2008). What the bat's voice tells the bat's brain. Proc. Natl. Acad. Sci. U.S.A. 105, 8491-8498. doi: 10.1073/pnas.07035 50105

Vila, A. R., Campagna, C., Iniguez, M., and Falabella, V. (2008). South American sea lions (Otaria flavescens) avoid killer whale (Orcinus orca) predation. Aquat. Mamm. 34, 317-330. doi: 10.1578/AM.34.3.2008.317
Vitaterna, M. H., Takahashi, J. S., and Turek, F. W. (2001). Overview of circadian rhythms. Alcohol Res. Health 25, 85-93. Available online at: http://pubs.niaaa.nih.gov/publications/arh25-2/85-93.htm

Wallin, N. L., Merker, B., and Brown, S. (2001). The Origins of Music. Cambridge, MA: MIT press.

Wieczorkowska, A., Synak, P., and Raœ, Z. W. (2006). "Multi-label classification of emotions in music," in Advances in Soft Computing, eds M. A. Klopotek, S. T. Wierzchon, and K. Trojanowski (Berlin: Springer-Verlag Berlin), 307-315.

Wood, G. A. (1984). Tool use by the palm cockatoo Probosciger aterrimus during display. Corella 8, 94-95.

Zatorre, R. J., Belin, P., and Penhune, V. B. (2002). Structure and function of auditory cortex: music and speech. Trends Cogn. Sci. 6, 37-46. doi: 10.1016/S13646613(00)01816-7

Zatorre, R. J., Chen, J. L., and Penhune, V. B. (2007). When the brain plays music: auditory-motor interactions in music perception and production. Nat. Rev. Neurosci. 8, 547-558. doi: 10.1038/nrn2152

Zatorre, R. J., and Salimpoor, V. N. (2013). From perception to pleasure: music and its neural substrates. Proc. Natl. Acad. Sci. U.S.A. 110, 10430-10437. doi: $10.1073 /$ pnas. 1301228110

Conflict of Interest Statement: The author declares that the research was conducted in the absence of any commercial or financial relationships that could be construed as a potential conflict of interest.

Received: 11 August 2014; accepted: 21 January 2015; published online: 18 February 2015.

Citation: Wang T (2015) A hypothesis on the biological origins and social evolution of music and dance. Front. Neurosci. 9:30. doi: 10.3389/fnins.2015.00030

This article was submitted to Auditory Cognitive Neuroscience, a section of the journal Frontiers in Neuroscience.

Copyright (C) 2015 Wang. This is an open-access article distributed under the terms of the Creative Commons Attribution License (CC BY). The use, distribution or reproduction in other forums is permitted, provided the original author(s) or licensor are credited and that the original publication in this journal is cited, in accordance with accepted academic practice. No use, distribution or reproduction is permitted which does not comply with these terms. 